\title{
Lidocaine/prilocaine cream (EMLA(R)) versus infiltration anaesthesia: a comparison of the analgesic efficacy for punch biopsy and electrocoagulation of genital warts in men
}

\author{
Gerdien M v d Berg, Stefan Lillieborg, Ernst Stolz
}

\begin{abstract}
Objectives-To compare analgesic efficacy and pain caused by administration of lidocaine/prilocaine cream (EMLA(R)) versus xylocaine $1 \%$ local infiltration for punch biopsy and electrocoagulation of genital warts in men.
\end{abstract}

Design-Open randomised comparative parallel-group study.

Setting-Department of Dermatovenereology, University Hospital Rotterdam/Dijkzigt, the Netherlands.

Patients -63 males with warts on the genital mucosa and/or perianal area. Methods-EMLA(R) cream (2.5-5 g) was applied during 13-45 minutes before surgery. Xylocaine $1 \%(0 \cdot 1-4 \mathrm{ml})$ was infiltrated $0.5-4$ minutes before surgery. Pain during administration and surgery was assessed by the patient on a verbal rating scale and on a visual analogue scale.

Results-EMLA(R) application was painless in all patients $(n=31)$ whereas xylocaine infiltration was slightly painful in $17 / 29$ patients and moderately painful in $10 / 29$ patients. EMLA(R) analgesia was satisfactory for $94 \%$ of biopsies and $62 \%$ of electrocoagulations. Xylocaine infiltration was satisfactory in all procedures.

Conclusions-EMLA(R) application on the male genital mucosa is painless but it has a lower analgesic efficacy than xylocaine infiltration. However EMLA is a useful anaesthetic for taking biopsies in this area and may be used as premedication for local infiltration.

Department of Dermatovenereology, University Hospital Rotterdam/Dijkzigt, The Netherlands G M v d Berg

E Stolz

Department of Clinical Research, Astra Pain Control AB, Södertälje, Sweden

S Lillieborg

Address correspondence to Gerdien M v d Berg Dr. Molewaterplein 40 3015 GD Rotterdam The Netherlands

Accepted for publication 17 December 1991

\section{Introduction}

Biopsies and the surgical treatment of condylomata acuminata are usually performed under local infiltration anaesthesia, which in itself is quite painful.

Lidocaine/prilocaine cream (EMLA(R)) provides superficial dermal analgesia after application to the occluded skin for at least one hour. ${ }^{1}$ In the vulval mucous membranes anaesthesia exists after 5 minutes, ${ }^{23}$ indicating faster absorption than through the skin. EMLA provides satisfactory analgesia for thermocautery ${ }^{2}$ or laser treatment ${ }^{3}$ of vulval condylomata and for diagnostic punch biopsies in women. ${ }^{4}$ When EMLA was applied to condylomata mainly located in the preputialcavity for 20-70 minutes, the degree of anaesthesia was adequate for thermocautery in $96 \%$ of the men. ${ }^{5}$ In a comparative study with xylocaine $(R)$ infiltration EMLA was recommended as the anaesthetic of choice for laser surgery of genital warts. ${ }^{6}$

Our study was performed to measure the pain caused by the administration of the local anaesthetics and the effectiveness of EMLA, compared with infiltration anaesthesia for biopsies and electrocoagulation of genital warts.

\section{Patients and methods}

Study design

The trial had an open randomised comparative parallel-group design. Stratification was used to obtain an equal distribution of patients with electrocoagulation and biopsies between the two groups. Sixty men (at least 20 patients for either procedure) with warts on the genital mucosa or perianal region were to be entered. On the day of treatment a sealed envelope, individual to each patient, was opened to reveal the treatment, which was randomised for EMLA or xylocaine.

No treatment should have been given in the previous 2 weeks. Exclusion criteria were allergy to local anaesthetics of the amide type and giant condylomata.

The study protocol was approved by the local ethics committee, University Hospital Rotterdam/Dijkzigt and the verbal consent of the patients was obtained prior to inclusion.

\section{Anaesthetic and surgical procedure}

After recording of the location of the warts a thick layer of approximately $2 \cdot 5-5 \mathrm{~g}$ (median $2.5 \mathrm{~g}$ ) of EMLA $5 \%$ cream, containing licocaine $25 \mathrm{mg}$ and prilocaine $25 \mathrm{mg}$ per gram, was applied over the lesions. In case of incomplete coverage of the cream by the prepuce, the area was covered with plastic film (Glad, First Brands, Germany). The surgical procedure was to start after an application time between 15 and 30 minutes.

Infiltration anaesthesia was obtained with $0.1-4 \mathrm{ml}$ (median $0.7 \mathrm{ml}$ ) xylocaine (R) $1 \%$ without adrenaline $(0.5 \mathrm{~mm}$ Monoject $(\mathrm{TM})$ needle), 5 minutes before the surgical procedure was started.

The presence of analgesia was tested with a pin-prick before the biopsy/electrocoagulation. 
The time of the test was recorded. Local reactions were assessed. Diagnostic biopsies were taken with a disposable 3 or $4 \mathrm{~mm}$ punch (Stiefel). The condylomata were removed with an electrocoagulator (Surgistat (TM), Valleylab) and the duration of the surgery was recorded. In more than $90 \%$ of the patients the same physician ( $\mathrm{v} \mathrm{d} \mathrm{Berg}$ ) performed the treatments and all assessments. If the procedure was painful, additional EMLA cream was given in the EMLA group and additional xylocaine in the infiltration group. The dose given, time to start of continued treatment and pain from the treatment were assessed.

\section{Assessment of pain}

Pain associated with the injection or application of the local anaesthetic was assessed by the patient on a $100 \mathrm{~mm}$ horizontal visual analogue scale $(\mathrm{VAS})^{7}$ with the end points no pain $(0 \mathrm{~mm})$ and intolerable pain $(100 \mathrm{~mm})$. The pain was also assessed by the patient on a verbal rating scale: no pain, slight pain (= quite tolerable), moderate pain ( $=$ not quite tolerable) and severe pain (= intolerable). Pain during the biopsy/surgery was assessed in the same way. If warts in multiple locations were treated and the pain differed between locations, the worst pain was recorded.

If surgery was interrupted due to pain, the pain assessment for the initial treatment was made before the administration of additional anaesthetic.

\section{Assessment of local reactions}

The patient was asked about local irritation before the start of the cautery. At the same time local erythema and oedema were assessed by the physician. The reactions were rated as none, slight, moderate or profound. The presence of any other reaction was recorded as "yes" or "no".
Table The patients' age and the location of the condylomata (all patients treated)

\begin{tabular}{lll}
\hline & $\begin{array}{l}\text { EMLA } \\
(n=32)\end{array}$ & $\begin{array}{l}X y \text { locaine } \\
(n=31)\end{array}$ \\
\hline $\begin{array}{l}\text { Age (years) } \\
\text { (median, range) }\end{array}$ & $32(16-70$ & $30(20-60)$ \\
$\begin{array}{l}\text { Location of warts } \\
\text { (No of patients) }\end{array}$ & \\
$\begin{array}{l}\text { Prepuce } \\
\text { Prepuce + one other site }\end{array}$ & 15 & 19 \\
$\begin{array}{l}\text { Prepuce + two other sites } \\
\text { Glans }\end{array}$ & 1 & 2 \\
Glans + one other site & 3 & 1 \\
Glans + two other sites & 3 & 1 \\
Sulcus & 1 & 1 \\
Frenulum & 3 & 0 \\
Perianal & 2 & 0 \\
Pubic area or shaft & 2 & 5 \\
\hline
\end{tabular}

\section{Statistics}

The difference in pain and severity of adverse reactions between the groups were analysed by use of an extended Mantel-Haenszel procedure, equal to the stratified Wilcoxon Rank Sum test $t^{8}$ which was stratified with respect to surgical procedure. The tests were two-tailed and a $p$ value of $<0.05$ was considered to be significant.

\section{Results}

Thirty-two patients were given EMLA and 31 xylocaine. The groups were comparable with regard to age and location of the treated area (table). ${ }^{3}$ Three patients were excluded from the statistical analysis of pain. Two patients in the xylocaine group had no warts on the mucous membranes but on the perigenital skin. One patient was randomised to xylocaine but was by mistake given EMLA.

Biopsies were taken in 18 patients in the EMLA group and 16 patients in the xylocaine group. The median application time of EMLA cream was 25 minutes and the surgical
Figure 1 Verbal pain assessment during injection of lidocaine and application of EMLA

$\left(p<0.001, \chi^{2}=47.12\right)$ and during the subsequen surgery or biopsy $\left(p=0.001, \chi^{2}=11.67\right)$.
No. of patients

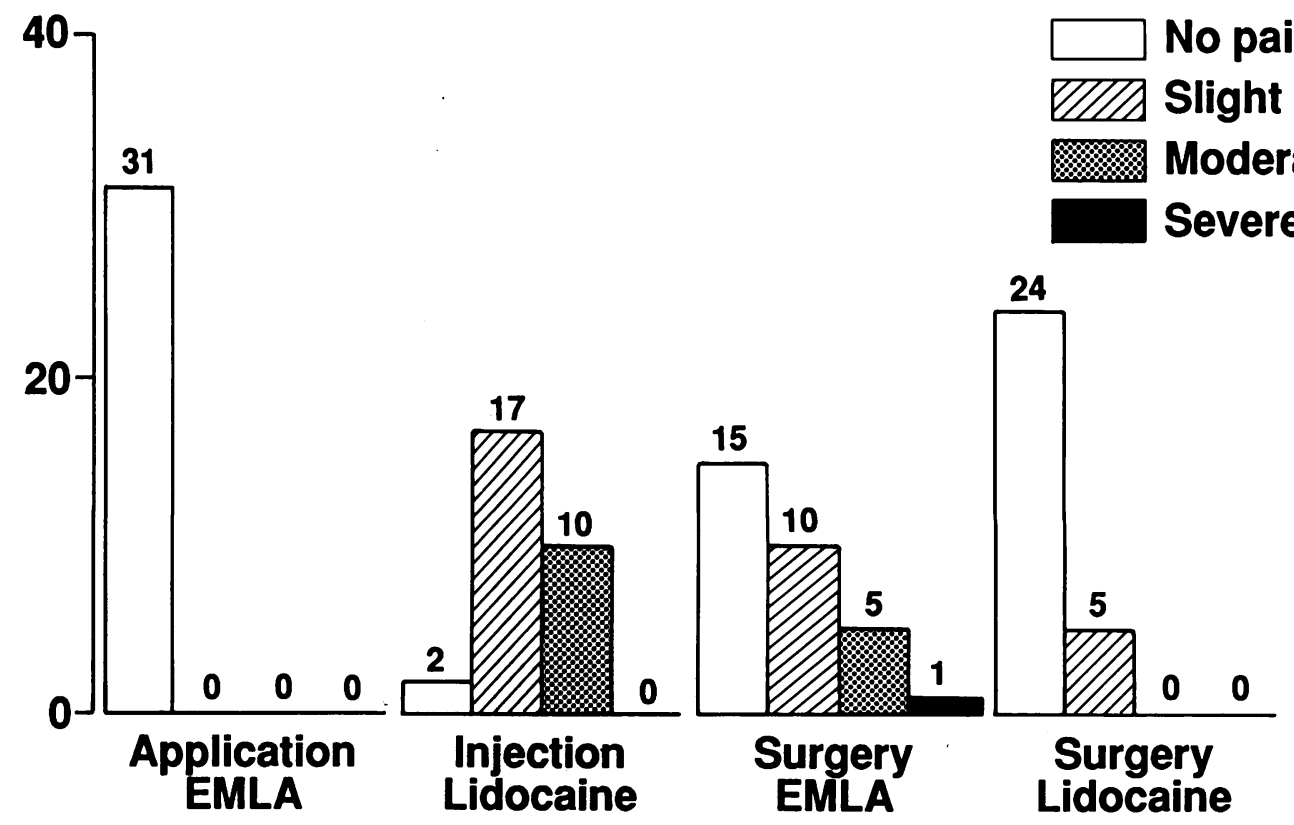


procedure was started within 5 minutes in all but 1 patient ( 15 minutes). The duration of surgery, median 5 minutes, and the size of the biopsy punches used ( 3 or $4 \mathrm{~mm}$ ) were comparable between the groups.

Pain from application/injection

No patient felt any discomfort from the application of EMLA, whereas the injection of xylocaine was rated as slightly painful by 17 and moderately painful by 10 patients ( $p<0.001$, fig 1$)$. The median VAS scores were 0 and 13 respectively ( $<<0.001$, fig $2 a$ ).

\section{Analgesic efficacy}

The pin-prick test prior to biopsy/surgery showed that anaesthesia was present in all but two patients. These patients had had EMLA applied to the glans for 15 minutes. They were given new EMLA cream for an additional 12 15 minutes.

The pin-prick test showed that analgesia was present and the surgical procedure was started 0.5 to 4 minutes after the injection in 24 patients in the xylocaine group instead of the intended 5 minutes. In the EMLA group five patients treated with electrocoagulation reported moderate pain and one patient with biopsy severe pain. No patient in the xylocaine group felt moderate or severe pain ( $p=0.001$, fig 1 ). The median VAS scores were 3.5 and 0 in the two groups respectively ( $p<0.001$, fig $2 b$ ).

Electrocoagulation tended to be more painful than punch biopsies: in all five patients in the xylocaine group who felt slight pain electrocoagulation was performed. In the EMLA group the median VAS score from biopsy was 2 and from electrocoagulation 14 (fig 3 ). In the EMLA group $94 \%(17 / 18)$ of biopsies were taken with no $(\mathrm{n}=11)$ or only slight pain $(n=6)$. Similarly, $62 \%(8 / 13)$ of electrocoagulations were performed with no $(n=4)$ or slight $(n=4)$ pain.

Treatment was interrupted due to pain after 25 minutes' electrocoagulation in one EMLA patient with extensive warts. Treatment was continued after 230 minutes of additional EMLA application but was again painful and surgery was stopped.

Local reactions

Slight burning was felt by three EMLA and
Figure 2 Individual pain scores (VAS) during injection of lidocaine and application of EMLA $\left(p<0.001, \chi^{2}=36.26\right)$ (a) and during the subsequent surgery or biopsy $\left(p<0.001, \chi^{2}=12.83\right)$ (b). The median score is indicated by the horizontal line (Md.). (The VAS score from biopsy is missing in one EMLA patient, who rated the pain as none on the verbal scale).

\section{Individual Pain Scores}
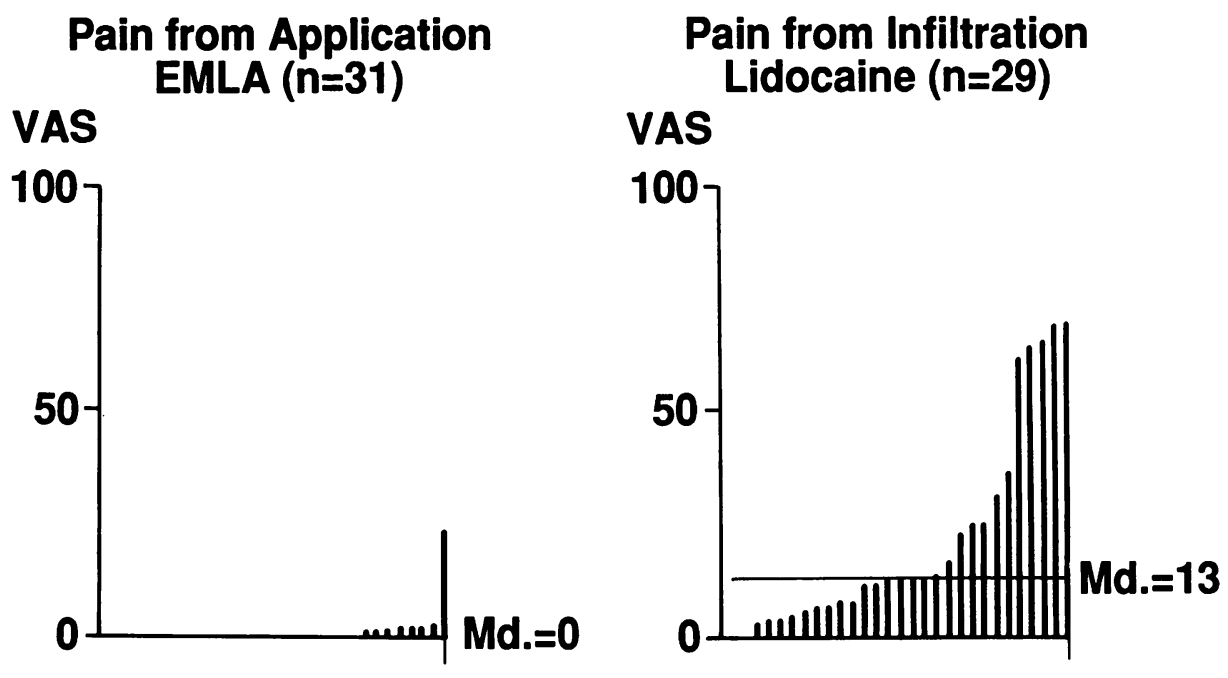

Pain from Surgery/Biopsy
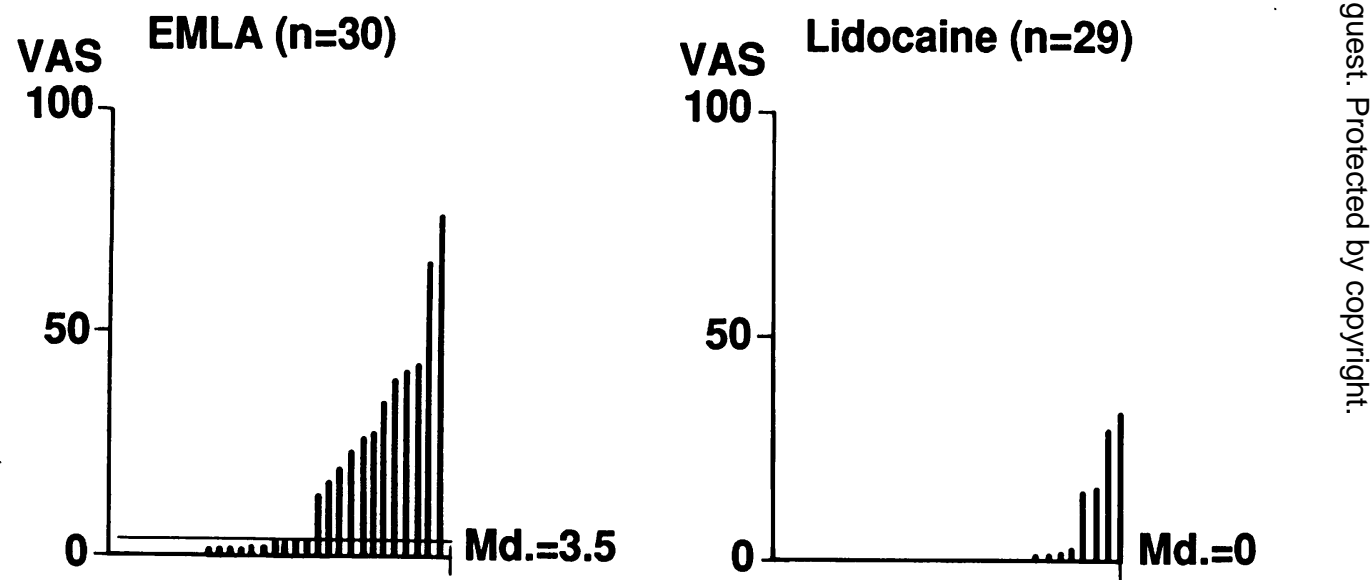
Figure 3 Individual pain scores (VAS) from biopsy or electrocoagulation in the two groups. The median score is indicated by the horizontal line (Md.). (The VAS score from biopsy is missing in one EMLA patient, who rated the pain as none on the verbal scale).

\section{Pain Scores}

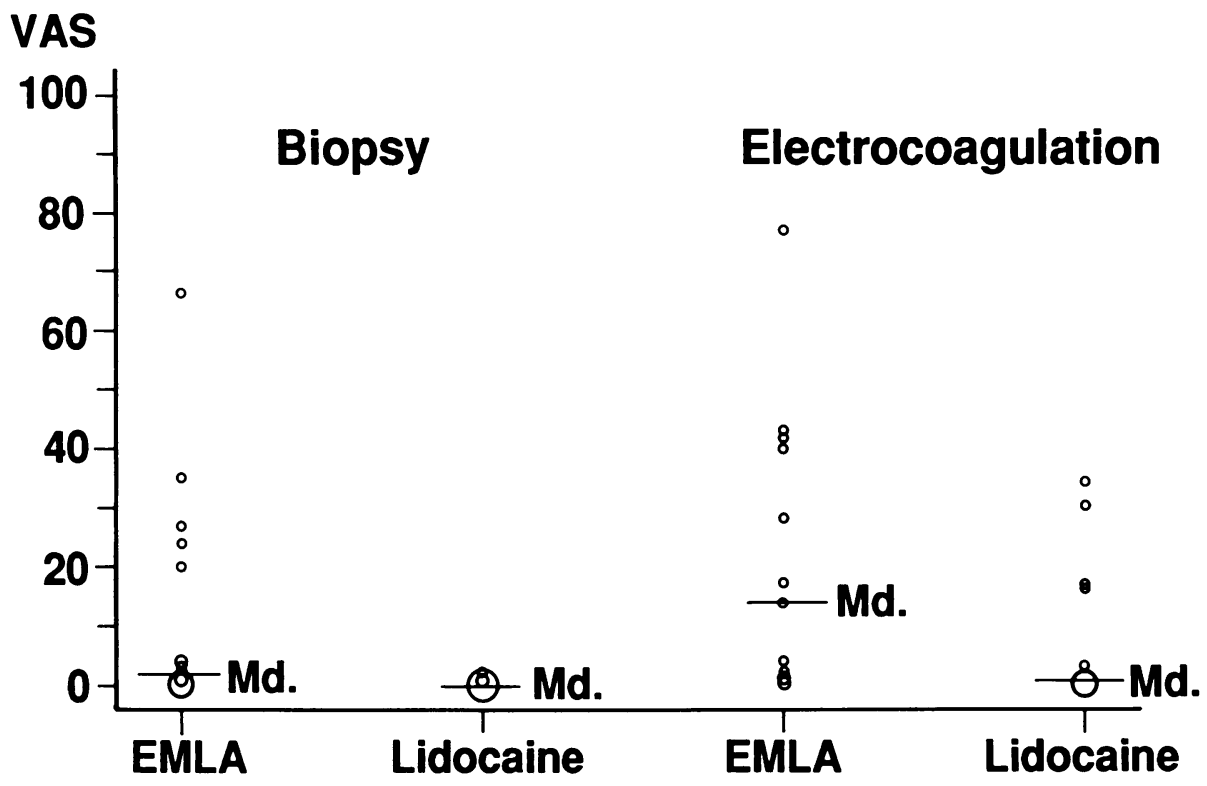

two xylocaine patients. Slight or moderate local oedema was observed in six and nine patients respectively ( $p=0.30, \chi^{2}=1.08$ ). Slight or moderate redness was more common in the EMLA group (14 patients) versus three in the xylocaine group $(\mathrm{p}=0.001)$.

The anaesthetised area was pale in eight EMLA patients and one xylocaine patient.

\section{Discussion}

In this study the injection of a local anaesthetic into the genital area was shown to cause pain in all but two patients, whereas application of EMLA cream was painless. Local reactions from the anaesthetics were mild and transient. EMLA analgesia was satisfactory (no or slight pain) for $94 \%$ of biopsies and $62 \%$ of electrocoagulations, where xylocaine was effective in all patients.

It is possible that the application times of EMLA cream used in this study (13-45 (median 25) minutes), were too long to provide optimal analgesia. In women the most effective degree of anaesthesia of the genital mucous membranes is obtained when EMLA is applied for 5-10 minutes; ${ }^{23}$ longer application times will result in decreased analgesic efficacy. This difference, compared to dermal analgesia which increases with application time from 15 to about 120 minutes, ${ }^{19}$ may be explained by faster absorption of the local anaesthetics from the well perfused genital tissues.

Hallen $e t a l^{5}$ reported that in nine men with meatal condylomata and 11 men with condylomata in the preputial cavity an application time of EMLA for 3-27 minutes (median 9.5 minutes) made possible painless thermocautery in 17 men and only slight pain in there. However, Lassus et $a l^{6}$ found in a study of $\mathrm{CO} 2$ laser treatment of condylomata that infiltration of xylocaine was more effective than 10 minutes' EMLA treatment. In that trial the proportion of EMLA-treated patients reporting moderate pain from surgery was the same as in the present study, $16-18 \%$. Similarly, in both studies one patient felt severe pain $(2-3 \%)$.
Electrocoagulation tended to be more painful than punch biopsies both in EMLA- and xylocaine-treated patients. In the EMLA group only one patient $(5 \%)$ felt moderate/ severe pain from biopsy, compared with $38 \%$ from electrocoagulation. This may be explained by the fact that electrocoagulation

In conclusion, pain and discomfort was less during the application of EMLA than during the infiltration of xylocaine. The infiltration of xylocaine resulted in better surgical anaesthesia. EMLA analgesia was satisfactory for $94 \%$ of biopsies and $62 \%$ of electrocoagulations. If the quality of EMLA anaesthesia for electrocoagulation cannot be improved by a modified application time it is suggested that EMLA cream may be used as premedication to decrease the pain from the local anaesthetic injection prior to electrocoagulation of genital warts in men.

1 Juhlin L, Evers H. EMLA: a new topical anaesthetic. Adv in Dermatology 1990;5:75-92.

2 Ljunghall $\mathrm{K}$, Lillieborg $\mathrm{S}$. Local anaesthesia with a lidocaine/prilocaine cream (EMLA (R)) for cautery of condylomata acuminata on the vulval mucosa. The effect of timing of application of the cream. Acta Derm Venereol (Stockh) 1989;69:362-5.

3 Rylander E, Sjöberg I, Lillieborg S, Stockman O. Localanaesthesia of the genital mucosa with a lidocaine prilocaine cream (EMLA (R)) for laser treatment of condylomata acuminata. A placebo-controlled study. Obs tet Gynecol 1990;75:302-6.

4 Byrne MA, Taylor-Robinson D, Pryce D, Harris JRW. Topical anaesthesia with lidocaine-prilocaine cream for vulval biopsy. Br J Obstet Gynaecol 1989;96:497-9.

5 Hallén A, Ljunghall $K$, Wallin J. Topical anaesthesia with local anaesthetic (lidocaine and prilocaine, EMLA) cream for cautery of genital warts. Genitourin Med 1987;63: 316-9.

6 Lassus A, Kartamaa M, Happonen H-P. A comparative study of topical analgesia with a lidocaine/prilocaine cream (EMLA (R)) and infiltration anaesthesia for laser surgery of genital warts in men. Sex Transm Dis surgery of ge

7 Scott J, Huskisson EC. Graphic representation of pain. Pain

8 Kuritz SJ, Landis RL, Koch GG. A General Overview of Mantel-Haenszel Methods: Applications and Recen Developments. Ann Rev Public Health. 1988;9:123-60.

9 Arendt-Nielsen L, Bjerrring P. Laser-induced pain fo evaluation of local analgesia: A comparison of topical application (EMLA) and local injection (Lidocaine) Anesth Analg 1988;67:115-23. generally lasted longer. 1976;2:175-84 